\title{
Analysis on Embodiment of Intercultural Communication Competence in ETIC Communication Tasks-Based on Hofstede's Cultural Dimensions Theory
}

\author{
LIU Fulan, XU Hanyan \\ Jiangxi Normal University, Jiangxi, China
}

\begin{abstract}
The English Test for International Communication (ETIC) is designed to investigate the core qualities that international talents are supposed to be equipped with, including the ability of fully understanding international rules and cooperation, the ability of analyzing and solving problems, as well as the ability of cross-cultural comprehension and expression. Under the guide of Hofstede's cultural dimensions theory, this paper tries to analyze some typical questions from the official website of ETIC and dip out the implied examining points of intercultural communication competence behind the questions of the communication tasks in ETIC. In this way, some enlightenment for improving cross-cultural communication ability can be provided.

Keywords: communication tasks in ETIC, intercultural communication competence, Hofstede's cultural dimensions theory
\end{abstract}

\section{Introduction}

As China's international exchanges at all levels become more frequent and its international influence enhances, the "One Belt and One Road" strategy continues to deepen and China's ability to participate in global governance constantly improves. As a result, the country's demand for talents with global vision, proficiency in foreign languages, and familiarity with international rules grows increasingly. Every college student facing career choice as well as professionals who intend to have broader career platforms all hope to have an authoritative examination to certify their English communication skills. Therefore, English Test for International Communication (ETIC), which is developed and implemented by China Language Assessment (CLA) Center, appears timely in response to the urgent need of the time and the country. With the design concept of "serving the workplace and focusing on communication", it aims to serve the training and selection of talents at all levels and has won recognition from all walks of life (Luo \& Han, 2018).

In this era of diverse and interconnected civilizations, intercultural competence has become a new requirement for high-quality talents in the 21 st century and the cultivation of intercultural competence has

LIU Fulan, Doctor's degree, professor; Master's supervisor, Foreign Languages College, Jiangxi Normal University, Jiangxi, China.

XU Hanyan, Master's degree, postgraduate student in school, Foreign Languages College, Jiangxi Normal University, Jiangxi, China. 
become the very meaning of foreign language education and reform. To master a language is to understand a culture and the ultimate goal of language learning is to achieve appropriate and effective intercultural communication; hence, language competence is closely related to intercultural competence (Sun, 2016). The cultivation of intercultural competence is not simply about the level of knowledge input, but more importantly, about how to internalize the knowledge into one's own intercultural competence and effectively carry out intercultural communication. The change of the goal of foreign language talent training puts forward new requirements for language testing and challenges the traditional testing which takes language competence as a single construct (Yang, 2018). Therefore, This paper intends to find out how ETIC integrates knowledge input with intercultural competence in the communication tasks under Hofstede's cultural dimensions theory.

\section{Features and Advantages of ETIC}

\section{Credible and Widely-Accepted}

The exam was developed by the authoritative China Language Assessment (CLA) Center and completed its first test in 2016. The national talent examination mainly examines the core qualities of international talents in the process of global integration, such as the ability to understand international rules, to analyze and solve problems, and to understand and express across cultures. As long as the corresponding strength is available, English learners and workers with any academic background can take the examination. Now, there are many multinational companies and large state-owned enterprises beginning to refer to the exam to recruit candidates.

\section{Clearly Classified and Output-Oriented}

According to the different needs of international exchange activities, the exam is divided into five categories, including advanced translation, high-end level, advanced level, intermediate level, and preliminary level. ETIC emphasizes output orientation and cultivates the ability to express effectively in English under different scenarios. All of the tests are used for assessing the ability of college students and social elites in applying English to conduct business in different occasions. In addition to professional knowledge, another important knowledge of "international talents" is that of international business, which is well reflected in the contents of ETIC intermediate level. Starting from the ability in the workplace, the concept of ETIC is very novel and it is helpful for job seekers and professionals. The content of ETIC intermediate level includes business contracts, business speeches, and other questions related to immediate response and thought organization. It mainly tests communication skills and focuses on intercultural communication, which is highly matched with the workplace.

\section{Highlighting Practical Integrated Ability}

ETIC converges the wisdom of language testing researchers both at home and abroad as well as the enterprise managers, updates the talent evaluation standard and further designs typical workplace communication tasks to examine the core quality that should be possessed by international talents: English communication skill, which mainly includes three dimensions-international vision and ability of negotiation and cooperation, intercultural understanding and expression ability, and the ability to analyze and solve problems (CLA, 2017).

Different from many examinations that are mainly for the purpose of teaching examination and entrance examination, the purpose and concept of ETIC to cultivate talents for communication are deeply rooted. The 
English name "English Test for International Communication" best explains the connotation of "English Communication Competence". For international talents, language ability is a necessity, and more important is the application of comprehensive ability, such as the ability of cross-cultural communication and how to understand people from other cultures, which are not tested by other tests. In addition, compared with other English tests, ETIC pays more attention to practical application of language and intercultural ability. For example, the oral communication tasks in ETIC advanced level obviously reflect the common oral communication scenes in the workplace.

\section{Cross-Cultural Communication Theory: Hofstede’s Cultural Dimensions Theory}

For cross-cultural communication, it is concluded that cross-cultural communication includes three levels: cognition, emotion, and behavior. Cognition refers to the cognition of both the culture of one's own country and the culture of another country. Emotional level is to have a sense of identity to one's own country's culture and to be able to recognize and tolerate foreign cultures, seeking common ground while reserving differences. At the behavioral level, cross-cultural communication is not only reflected in language, but also in non-verbal logic thinking, body expressions, gestures, and so on (Chen, 2009).

When it comes to cross-cultural communication, there are various definitions and rich theories, among which Hofstede's cultural dimensions theory is one of the most well-known. Hofstede's cultural dimensions theory is a framework proposed by Geert Hofstede, a Dutch psychologist, to measure cultural differences between different countries. Hofstede believed that culture was a psychological process shared by people in an environment, which could distinguish a group of people from others. Through the research, he summarized the differences between different cultures into five basic dimensions of cultural values (Hofstede, 2008).

(1) Power distance refers to the degree to which people of low status in a certain society accept the unequal distribution of power in society or organizations. Due to the different understanding of power in different countries, there are great differences in this dimension. Europeans and Americans do not value power as much as they value personal ability, while Asian countries focus on the binding force of power due to their systems.

(2) Uncertainty avoidance refers to whether a society avoids and controls uncertainty through formal channels when facing uncertain events and threats. High avoidance cultures place a high value on authority, status, seniority, and age, and try to avoid these situations by establishing more formal rules and trusting in absolute knowledge and expert evaluation. On the contrary, low avoidance cultures are more tolerant of abnormal behavior and opinions with fewer rules, and allow a variety of philosophical and religious opinions to coexist.

(3) Individualism vs. collectivism dimension is the measure of whether a society focuses on personal interests or concerns the interests of the collective on the whole. In the individualistic society, the relationship among individuals is loose and people tend to care about themselves and their small families. However, collectivist societies tend to focus on inter-ethnic relations and care about extended families. Strong ethnic relations can provide people with protection, while individuals must be absolutely loyal to the ethnic groups.

(4) Masculinity vs. femininity dimension depends mostly on whether a society values male qualities, such as competitiveness and arbitrariness, or represents the female qualities such as humility and love, and on how the society defines the functions of men and women. The greater the Masculinity Dimension Index (MDI) is, the more prominent the masculinity is. Conversely, it indicates that the society's femininity is more outstanding. 
(5) Long-term vs. short-term dimension refers to the extent to which the members of a culture can delay the satisfaction of their material, emotional, and social needs. This dimension shows the extent to which a moral life is worth pursuing without the need for any religion to justify it. Long-term orientation index has a strong relationship with the economic growth of various countries.

\section{Examination of Cross-Cultural Ability in the Communication Tasks of ETIC}

International talents are supposed to understand and respect the cultural differences of different countries and groups, and communicate effectively across these differences. Relevant knowledge should be applied to find, analyze, and solve problems in real work in a logical, systematic, and orderly way. Intercultural communication has been unconsciously hidden in all aspects of our life and the exam ETIC examines the intercultural communication competence of talents through different communication tasks. ETIC consists of two types of communication tasks, oral and written tasks, and each part is made up of three to four tasks. This paper picks out some typical questions from the official website of English Test for International Communication, attempting to analyze the reasons and examining points behind the questions with Hofstede's cultural dimensions theory.

\section{Preliminary Level of English Test for International Communication}

With regard to Task 4 of the written communication tasks in preliminary level, candidates are required to write a memo or an email according to the given topic and points. This task is designed to examine the candidates' ability of illustrating situations to a certain object with a certain identity based on a set context.

Task 4: You are Jones Cooper, secretary in the Customer Service Department of an international hotel. You are informed that construction will begin near the hotel and may cause some noises. Write an email to all the guests: To let them know when construction work will start and finish each day; to let them know where the construction work will take place; to apologize to them for any inconvenience caused. Write 50 words within 20 minutes.

In the situation set above, the candidate works in an international hotel and he or she should write an email to all the guests to inform them about the detailed information of the construction work near the hotel and make an apology for any inconvenience caused. This written task examines the intercultural communication ability of the candidate, for what the candidate expresses and the way he or she expresses are of great significance to the result of the notice.

According to Hofstede's uncertainty avoidance theory, Chinese culture belongs to high uncertainty avoidance culture while eastern cultures belong to low uncertainty avoidance ones. High uncertainty avoidance culture believes that uncertainty will easily cause anxiety and it is a threat which must be overcome while low uncertainty avoidance culture accepts uncertainty and bears little pressure. As a result, for those who have little tolerance for uncertainty, they are not likely to tolerate the uncertainty in time and place, which means that the candidate is bound to confirm the accurate time of when the construction work will start and finish each day (for example, the construction work starts from 8:30 a.m. and finishes at 6:00 p.m. each day) and inform the guests of the place the construction work will be carried out (for example, the construction takes place at Shengli Street, southwest of the gate of the hotel, 800 meters away).

\section{Intermediate Level of English Test for International Communication}

The oral communication tasks of intermediate level include four tasks: analysis of statements, data 
illustration, business introduction, and business speech. In Task 4, candidates are allowed to make a preparation on the topics of daily work and then deliver a speech in one minute. This task is designed to examine the candidates' ability of conveying information and illustrating the problems to a certain object as well as the ability of persuading others with a certain identity according to a fixed context.

Task 4: You are a training coordinator at the Human Resources Department at D-Toys International. Give a presentation to employees in the Marketing Department. Your purpose is to encourage them to join a cross-cultural communication training program. You should cover the following points: Understanding overseas markets; advantages of working with colleagues from foreign countries; opportunities to live and work in foreign countries. You have 90 seconds to prepare and 60 seconds to speak.

According to the given situation, the candidate is a training coordinator at an international company and he or she will give a presentation to employees so as to encourage them to take part in an intercultural communication training program. This oral task examines the integrated intercultural communication quality of the candidate, for he or she should have a good knowledge of overseas markets, understand the advantages of working with colleagues from foreign countries, and illustrate the opportunities to live and work in foreign countries.

Within Hofstede's power distance theory, the countries under the influence of eastern culture have high power distance index and people usually react to the inequality with indifference or tolerance. However, the power distance index under the influence of western culture is low, and the "power consciousness" is deeply rooted in people's heart, which makes them strongly resist the inequality of power distribution. Individuals under the western culture own obvious consciousness of individual right and weak rank orientation. For instance, in Malaysia (according to Hofstede's research, its power distance index stays at the top of the list), it is typical of being highly centralized with strict hierarchy, for everything is decided by management and the leaders must be obeyed. On the contrary, in a country with low power distance index like America, the relationship between management and staff is more equal, so people pay more attention to team spirit and will involve more in the process of decision-making. Therefore, the candidate can describe the advantage of working with colleagues from foreign countries as developing a more equal and harmonious relationship without tolerating unequal phenomena.

\section{Advanced Level of English Test for International Communication}

The written communication tasks of advanced level include three tasks, letter writing, report writing, and proposal writing. In Task 3, candidates are required to write a business proposal in which they need to put forward a certain suggestion and demonstrate it. This task aims to examine the candidates' abilities of illustrating purpose, analyzing current status and explaining the demand to a certain object with a certain identity in a fixed context.

Task 3: You work for a computer manufacturer in China, and your company is considering opening up a new branch in the United States. You are asked to analyze possible problems your company might encounter, and offer your solutions. Write to your CEO a proposal including the following information: A brief description of the U.S. market; reasons for setting up a new branch abroad; problems your company might encounter; possible solutions to these problems. Write about 300 words within 40 minutes. 
Based on the set situation, the candidate is an employee at a Chinese company and he or she is asked to analyze some problems the new branch company will encounter and give the solutions. This oral task also examines the intercultural communication quality of the candidate, for he or she should know U.S. market well, predict the possible problems and offer plausible solutions.

Within Hofstede's cultural dimensions theory, the dimensions of individualism vs. collectivism, masculinity vs. femininity, and long-term vs. short-term ought to be considered into the possible problems the company might encounter. China and America belong to different cultures, which means that knowing and understanding the cultural differences between them facilitates smooth communication and paves the way for international business.

First of all, China values community and the United States values the individual. If you achieve something in the United States, it is because you are excellent. While in China, if you make achievements, it is because the team, family or the company is remarkable. What is more, Chinese people do not have the same concept of privacy as Americans do. They talk about topics such as age, income or marital status, which Americans think is annoying and intrusive. Thirdly, from the long- and short- term dimension, Chinese people like to save for the long-term development. But it is different in America, where families and companies spend money to enjoy the current happiness. Last but not least, Americans advocate freedom and equality, maintaining that men and women are equal in the workplace whereas in China, women are in weak position and are discriminated from time to time, finding that being promoted to management takes more effort than men. To deal with these cultural differences, the best solution is to cultivate the employees' awareness of the intercultural differences, establishing equal relationship with others and show respect where differences occur.

\section{Conclusion}

English Test for International Communication responds to social needs and selects national talents for the country and international companies. By analyzing the communication tasks of three categories with Hofstede's cultural dimensions theory, it is concluded that ETIC tests the intercultural communication competence integratedly. As an international talent, it is essential to have a global vision and participate in international affairs with excellent intercultural communication ability.

\section{References}

Chen, G. M. (2009). Foundations of intercultural communication. Shanghai: East China Normal University Press.

China Language Assessment (CLA) Center. (2017). Official guideline of English Test for International Communication. Beijing: Foreign Language Teaching and Research Press.

Hofstede, G. (2008). Communication across cultures: Comparing values, behaviors, institutions and organizations across nations. Shanghai: Shanghai Foreign Language Education Press.

Hu, W. Z. (1994). Culture and communication. Beijing: Foreign Language Teaching and Research Press.

Li, W. J. (2009). The Hofstede's cultural dimension and cross-cultural studies. Social Sciences, (12), 126-129.

Luo, K. Z., \& Han, B. C. (2018). The construct definition, task design and evaluation method of ETIC. Foreign Language Education in China (Quarterly), (11), 40-46.

Sun, Y. Z. (2016). Foreign language education and intercultural competence. Chinese Foreign Languages, 1(3), 17-22.

Yang, L. F. (2018). Language test task design integrating critical thinking ability and intercultural communication ability-take ETIC as an example. Foreign Language World, (2), 49-56. 